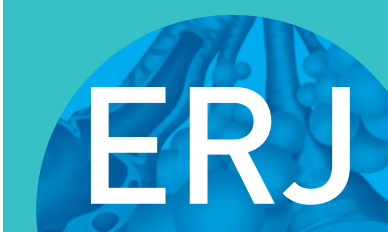

open research
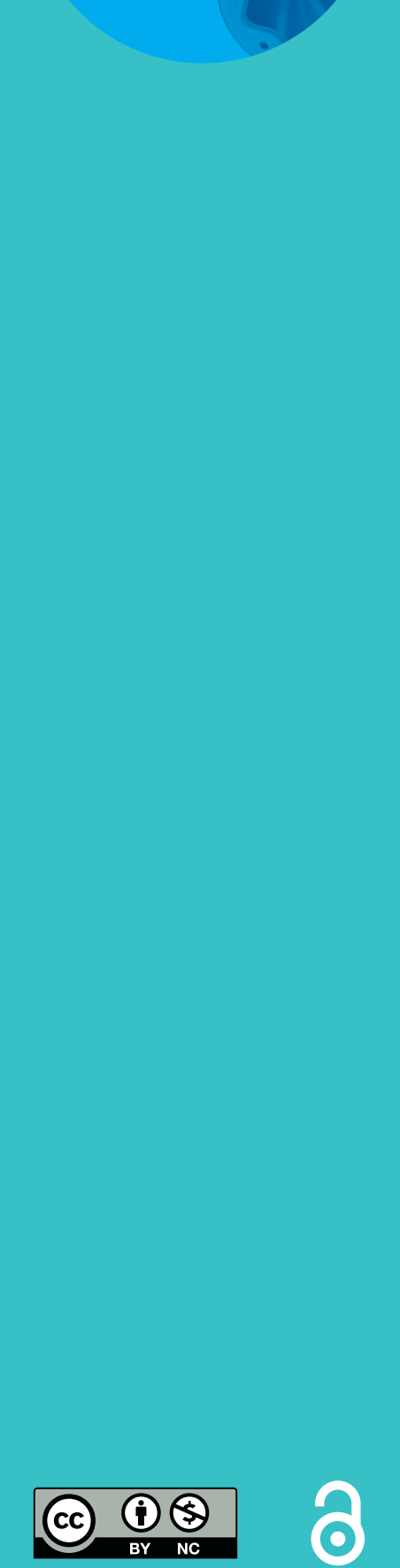

\section{Sex-specific differences and survival in patients with idiopathic pulmonary arterial hypertension 2008-2016}

\author{
Barbro Kjellström (1) ${ }^{1}$, Magnus Nisell², David Kylhammar ${ }^{3}$, Sven-Erik Bartfay ${ }^{4,5}$, \\ Bodil Ivarsson (1) ${ }^{6,7}$, Göran Rådegran $\mathbb{1}^{6}$ and Clara Hjalmarsson $\mathbb{1}^{4}$ on behalf of \\ SveFPH and SPAHR
}

Affiliations: ${ }^{1}$ Cardiology Unit, Dept of Medicine, Karolinska Institutet, Stockholm, Sweden. ${ }^{2}$ Lung Unit, Dept of Medicine, Karolinska Institutet and Karolinska University Hospital, Stockholm, Sweden. ${ }^{3}$ Depts of Medical and Health Sciences, and Clinical Physiology, Linköping University, Linköping, Sweden. ${ }^{4}$ Dept of Molecular and Clinical Medicine, Sahlgrenska Academy, Gothenburg University, Gothenburg, Sweden. ${ }^{5}$ Dept of Cardiology, Sahlgrenska University Hospital, Gothenburg, Sweden. ${ }^{6}$ Dept of Clinical Sciences Lund, Cardiology, Lund University and Skåne University Hospital, Lund, Sweden. 7Dept of Cardiothoracic Surgery, Skåne University Hospital, Lund, Sweden.

Correspondence: Barbro Kjellström, Dept of Cardiology Research, Karolinska University Hospital, Solna, Building S1:02, S-171 76 Stockholm, Sweden. E-mail: barbro.kjellstromaki.se

\section{ABSTRACT}

Background: Women with idiopathic pulmonary arterial hypertension (IPAH) have been found to have a worse haemodynamic status at diagnosis, but better survival than men. Over the past decade, demographics have changed and new treatments have become available. The objective of this study was to investigate sex differences in an incident IPAH population diagnosed between 2008 and 2016.

Methods: Differences in clinical characteristics of patients included in the Swedish Pulmonary Arterial Hypertension Register (SPAHR) were analysed at the time of diagnosis. Survival by sex was investigated using Cox proportional hazard regression and Kaplan-Meier curves.

Results: The study included 271 patients diagnosed with IPAH, median age was 68 (1st-3rd quartiles 54-74) years and 56\% were women. At diagnosis, women were younger, had lower pulmonary vascular resistance and fewer comorbidities and more often received a combination of PAH-targeted therapies than men. Men had worse survival rates than women (hazard ratio 1.49; CI 1.02-2.18; $\mathrm{p}=0.038$ ), but this difference did not remain after adjustment for age (hazard ratio 1.30; CI 0.89-1.90; $\mathrm{p}=0.178$ ).

Conclusions: Men with incident IPAH have worse crude survival than women. This is due to women being younger with a less pronounced comorbidity burden than men at the time of diagnosis.

@ERSpublications

Despite minor differences in baseline characteristics between men and women, survival among patients with incident IPAH diagnosed 2008-2016 does not appear to be related to sex http://bit. ly/2JFgXhd

Cite this article as: Kjellström B, Nisell M, Kylhammar D, et al. Sex-specific differences and survival in patients with idiopathic pulmonary arterial hypertension 2008-2016. ERJ Open Res 2019; 5: 00075-2019 [https://doi.org/10.1183/23120541.00075-2019].

Received: 18 March 2019 | Accepted after revision: 18 June 2019

Copyright $\odot$ ERS 2019. This article is open access and distributed under the terms of the Creative Commons Attribution Non-Commercial Licence 4.0. 


\section{Introduction}

Pulmonary arterial hypertension (PAH) is a debilitating disease characterised by structural changes of the small pulmonary arteries and subsequent increased pulmonary vascular resistance, ultimately leading to right heart failure and death [1]. However, with modern PAH-targeted therapies and improved treatment strategies, the overall outcome of patients with $\mathrm{PAH}$ has improved considerably during the last decade [1-3].

Traditionally, idiopathic PAH (IPAH) has been considered a disease predominantly affecting women $[4,5]$; however, recent studies suggest that while women are still in the majority among the younger patients, the distribution of men and women is more equal among older patients with IPAH [6-8]. Several reasons for the higher female prevalence have been proposed, such as the role of sex hormones [9], autoimmunity or an X-linked locus in disease predisposition [10]. Nevertheless, no definitive pathogenetic mechanism supporting the association between female sex hormones and PAH has been identified.

It has been suggested that women with IPAH, familial, and/or anorexigen-associated PAH have better survival rates than men [11-14]. It has also been suggested that men have worse residual volume function than women at the time of diagnosis [11, 15]. However, previous studies comparing sex differences included younger populations with a mean age at diagnosis around 50 years $[11,13,15]$. This differs from the most recent registry reports where the mean age often exceeds 60 years [6-8]. Moreover, recent improvements in treatment strategies have changed the outcome for these patients [3] and this might not be reflected in the earlier studies.

The aim of the present study was to investigate sex-related differences in baseline characteristics and outcome among incident patients with IPAH diagnosed between 2008 and 2016 and included in the Swedish PAH Register (SPAHR; 6, 16).

\section{Material and methods}

Data recorded in SPAHR $[6,16]$ were used for the present study. All Swedish PAH centres participate in SPAHR and thereby enable a high national coverage $[6,16]$. SPAHR was approved by the National Board of Health and Welfare and by the Swedish Data Protection Authority. All patients were informed about their participation and had the right to decline. The present study complies with the Declaration of Helsinki and was approved by the local ethics committee in Gothenburg, Sweden (Dnr. 2015/1002).

\section{Study population}

Adult, incident patients diagnosed with IPAH between January 2008 and July 2016 and registered in SPAHR were included in the study. The IPAH diagnosis was made by right heart catheterisation according to the European Society of Cardiology (ESC) and European Respiratory Society (ERS) guidelines for the diagnosis and treatment of pulmonary hypertension effective at that time [1, 17]. Baseline was defined as the day of diagnosis. Results are presented for the total population, but to be comparable with previous studies, where the mean age was $48-53$ years [11, 13, 15], results in the present study were also dichotomised in age groups $<65$ years and $\geqslant 65$ years. In the present study, the mean age in the $<65$ years group was 48 years.

\section{Variables}

SPAHR baseline data include demographics, World Health Organization functional class (FC), haemodynamic parameters obtained by right heart catheterisation, 6-minute walking distance (6 MWD), blood biochemistry, comorbidities and medical treatments. Creatinine levels were used to estimate glomerular filtration rate (eGFR) according to the Cockcroft-Gault formula [18].

\section{Statistical methods and data management}

The Kruskal-Wallis test was used for statistical comparisons of continuous variables between the study groups. For categorical variables, differences were tested by using the Chi-square test or, in the case of low expected frequencies, Fisher's exact test. Survival differences were analysed by use of the Kaplan-Meier method and the log-rank test, as well as Cox proportional hazards models. Patients were censored at lung transplantation or June 29, 2016. Results are presented as the hazard ratio (HR) with a 95\% confidence interval (CI). In addition, descriptive statistics were used to characterise the data. All analyses were carried out using SAS statistical software (SAS system for Windows 9.4, SAS Institute Inc., Cary, NC, USA) and the $5 \%$ level of significance was chosen.

\section{Results}

There were 271 patients with IPAH available for analysis, of which 151 (56\%) were women. The median age was 68 (1st-3rd quartiles 54-74) years and the median follow-up time was 3.8 (1.9-6.0) years. During 
the course of the study period, 107 patients (52 women and 55 men) died and 14 patients (11 women and 3 men) underwent lung transplantation. At the time of diagnosis, women were younger, had lower pulmonary vascular resistance (PVR) and fewer comorbidities (in particular atrial fibrillation and ischaemic heart disease) than men (table 1). While women more often received an upfront combination of PAH-targeted treatment than men (table 1), there were no differences between sexes in the proportion that received baseline treatment with an endothelin receptor antagonist (ERA; women 53\% versus men 53\%, NS) or a phosphodiesterase inhibitor (PDEi; women $40 \%$ versus men $37 \%$, NS).

The 1-, 3- and 5-year survival rates were 88, 74 and 68\% for women and 78, 62 and 55\% for men, respectively (figure 1a). Survival rates were worse for men than for women (HR 1.49; CI 1.02-2.18; $\mathrm{p}=0.038$ ), but this difference did not remain after adjustment for age (HR 1.30; CI 0.89-1.90; $\mathrm{p}=0.178$ ) or when adjusting for relevant variables that differed between the sexes; age, PVR, atrial fibrillation, ischaemic heart disease and PAH-targeted treatment regime (HR 1.38; CI 0.89-2.15; $\mathrm{p}=0.152$ ).

Age group $<65$ years

Among patients $<65$ years, $67 \%$ were women. There were no differences in baseline characteristics between women and men (table 2).

\section{TABLE 1 Baseline characteristics by age and sex}

\begin{tabular}{|c|c|c|c|}
\hline & Women $(n=151)$ & Men $(n=120)$ & p-value \\
\hline Age years & $65(49-72)$ & $70(60-74)$ & 0.004 \\
\hline WHO-FC I/II/III/IV & $3 / 18 / 114 / 16(2 \% / 12 \% / 75 \% / 11 \%)$ & 1/28/81/10 (1\%/23\%/68\%/8\%) & 0.088 \\
\hline BMI $\mathrm{kg} \cdot \mathrm{m}^{-2}$ & $26(23-30)$ & $26(23-29)$ & 0.274 \\
\hline 6MWD m & $232(180-349)$ & 277 (178-415) & 0.307 \\
\hline SBP mmHg & $129(110-145)$ & 131 (119-148) & 0.114 \\
\hline$D_{\text {Lco }} \%$ predicted & $47(32-66)$ & $43(30-60)$ & 0.415 \\
\hline eGFR $\mathrm{mL} \cdot \mathrm{min}^{-1}$ per $1.73 \mathrm{~m}^{2}$ & $59(41-81)$ & $59(43-80)$ & 0.990 \\
\hline NT-proBNP ng. $\mathrm{L}^{-1}$ & 1597 (590-2979) & 1650 (741-4239) & 0.729 \\
\hline \multicolumn{4}{|l|}{ Comorbidities } \\
\hline Hypertension & $59(43 \%)$ & $60(57 \%)$ & 0.064 \\
\hline Diabetes mellitus & $32(23 \%)$ & $37(35 \%)$ & 0.067 \\
\hline Atrial fibrillation & $16(12 \%)$ & $25(24 \%)$ & 0.023 \\
\hline Ischaemic stroke & $6(4 \%)$ & $10(9 \%)$ & 0.200 \\
\hline Ischaemic heart disease & $13(9 \%)$ & $29(27 \%)$ & 0.001 \\
\hline \multicolumn{4}{|l|}{ Number of comorbidities } \\
\hline 0 comorbidities & $60(44 \%)$ & $24(23 \%)$ & \\
\hline 1 comorbidity & 42 (31\%) & $27(25 \%)$ & $<0.001$ \\
\hline$\geqslant 2$ comorbidities & $35(25 \%)$ & $55(52 \%)$ & \\
\hline \multicolumn{4}{|l|}{ Haemodynamic values } \\
\hline mRAP $\mathrm{mmHg}$ & $7(4-11)$ & $7(4-10)$ & 0.991 \\
\hline mPAP mmHg & $48(42-55)$ & $46(40-52)$ & 0.131 \\
\hline PAWP mmHg & $8(6-11)$ & $8(6-11)$ & 0.730 \\
\hline Cardiac index $\mathrm{L} \cdot \mathrm{min}^{-1} \cdot \mathrm{m}^{-2}$ & $2.2(1.8-2.6)$ & $2.2(1.8-2.5)$ & 0.904 \\
\hline PVR Wood units & $10(8-13)$ & $9(6-12)$ & 0.004 \\
\hline \multicolumn{4}{|l|}{ PAH-targeted therapy } \\
\hline Single & $105(70 \%)$ & $98(82 \%)$ & \\
\hline Dual & $32(21 \%)$ & $13(11 \%)$ & 0.046 \\
\hline Triple & $3(2 \%)$ & 0 & \\
\hline No treatment & $11(7 \%)$ & $9(8 \%)$ & \\
\hline \multicolumn{4}{|l|}{ Supportive therapy } \\
\hline Anticoagulants & $92(61 \%)$ & $75(63 \%)$ & 0.791 \\
\hline Diuretics & $103(68 \%)$ & $82(68 \%)$ & 0.983 \\
\hline Supplemental oxygen & $47(31 \%)$ & $41(34 \%)$ & 0.596 \\
\hline
\end{tabular}

Data are presented as median (interquartile range) or $\mathrm{n}(\%)$ unless otherwise stated. WHO-FC: World Health Organization functional class; BMI: body mass index; 6MWD: 6-min walking distance; SBP: systolic blood pressure; $D_{\mathrm{LCO}}$ : diffusing capacity of the lung for carbon monoxide; eGFR: estimated glomerular filtration rate; NT-proBNP: N-terminal pro-brain natriuretic peptide; mRAP: mean right atrial pressure; mPAP: mean pulmonary arterial pressure; PAWP: pulmonary arterial wedge pressure; PVR: pulmonary vascular resistance; PAH: pulmonary arterial hypertension. 

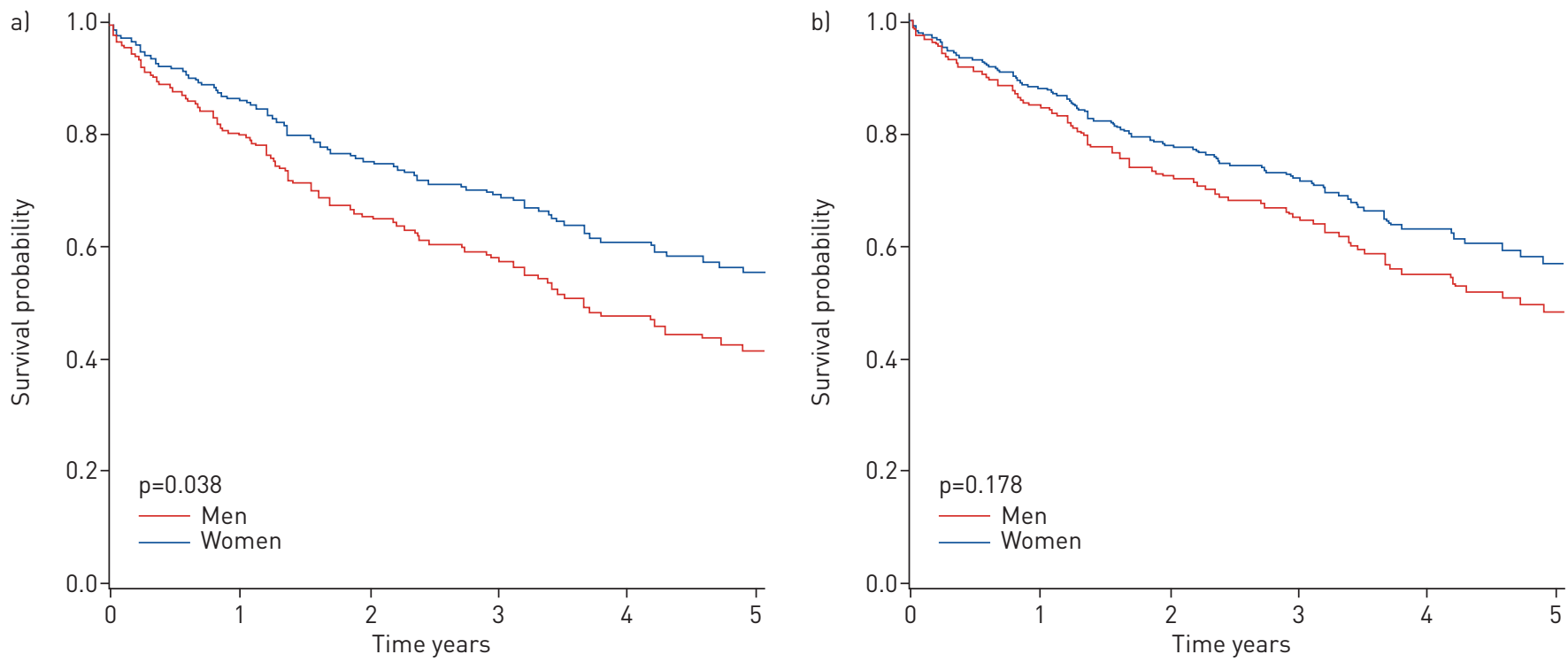

FIGURE 1 Survival of patients ( $\mathrm{n}=271$ ) stratified by sex. a) Unadjusted; b) adjusted for age.

There was no significant difference in 1-, 3- and 5-year survival rates between women (91, 86 and 70\%) and men $(92,83$ and $76 \%$ ) (figure $2 \mathrm{a}$ ). Sex was not a predictor of survival among patients $<65$ years (HR 0.81; CI 0.31-2.09; $\mathrm{p}=0.193$ ) and this remained after adjustment for age (HR 0.91; CI 0.35-2.37; $\mathrm{p}=0.853$ ).

Age group $\geqslant 65$ years

In the age group $\geqslant 65$ years, $48 \%$ were women. Women had higher PVR, lower eGFR and less history of ischaemic heart disease than men (table 2).

There was no significant difference in 1-, 3- and 5-year survival rates between women (84, 55 and 42\%) and men (72, 45 and 25\%) (figure $2 \mathrm{~b}$ ). Sex was not an independent predictor of survival among patients $\geqslant 65$ years (HR 1.41; CI 0.92-2.16; $\mathrm{p}=0.118$ ) and this remained after adjustment for age, PVR and history of ischaemic heart disease (HR 1.25; CI 0.77-2.02; $\mathrm{p}=0.370$ ).

\section{Discussion}

In the present study, men with incident IPAH had worse crude survival rates than women, but after adjusting for age, the difference in survival between the sexes disappeared. This may be explained by men being on average 5 years older and having a higher comorbidity burden than women at time of IPAH diagnosis. Apart from a slightly higher PVR among women (in particular in women $\geqslant 65$ years) baseline haemodynamics did not differ between the sexes. These findings contradict earlier studies where men with PAH had worse right ventricular function at the time of diagnosis [11, 15] and worse survival rates than women [11-14, 19]. In three of these earlier studies, patients were diagnosed at a mean age around 50 years $[11,13,15]$, making the results comparable to the younger group of patients in the present study ( $<65$ years), where no difference in diagnostic measures or survival was found. One of the previous studies that stratified patients by age in a manner similar to the present study, found a sex-related difference in mortality, despite baseline haemodynamic and demographic characteristics being comparable to the present study [12]. While the mortality rate was reported for patients with IPAH, familial and/or anorexigen-associated $\mathrm{PAH}$, the baseline characteristics were reported for the whole PAH group [1] and so, this comparison should be interpreted with caution.

An early positive treatment response, with improvement of clinical, functional, and haemodynamic parameters [1], has been shown to result in a similar survival benefit as having a stable low-risk profile at the time of diagnosis $[2,20-22]$. Thus, access to several treatment options and better understanding of treatment strategies, including the benefits of combination therapy [23, 24], might have contributed to reducing, not only the total mortality, but also the sex-related differences in survival seen in previous studies [25]. It has been suggested that women may benefit more from ERAs than men and that men may benefit more from a PDEi than women [25, 26]; however, findings from studies with a direct comparison between an ERA and PDEi did not support this $[27,28]$. In the present study, there was no sex-related difference in the proportion of patients that received an ERA or a PDEi; however, more women than men received a combination treatment upfront, indicating a more aggressive initial treatment and this could 
TABLE 2 Baseline characteristics by age and sex

\begin{tabular}{|c|c|c|c|c|c|c|}
\hline & \multicolumn{3}{|c|}{$<65$ years } & \multicolumn{3}{|c|}{$\geqslant 65$ years } \\
\hline & Women $(n=72)$ & Men $(n=36)$ & p-value & Women $(n=79)$ & Men ( $n=84)$ & $p$-value \\
\hline Age years & $48(35-61)$ & 48 (39-58) & 0.870 & 73 (69-77) & $74(70-78)$ & 0.409 \\
\hline WHO-FC I/II/III/IV & $2 / 13 / 45 / 12$ (3\%/18\%/62\%/17\%) & $1 / 15 / 16 / 4$ (3\%/42\%/44\%/11\%) & 0.070 & $1 / 5 / 69 / 4(1 \% / 6 \% / 87 \% / 5 \%)$ & 0/13/65/6 (0\%/16\%/77\%/7\%) & 0.177 \\
\hline $\mathrm{BMI} \mathrm{kg} \cdot \mathrm{m}^{-2}$ & $26(23-30)$ & $27(23-29)$ & 0.958 & $27(24-30)$ & $26(24-28)$ & 0.072 \\
\hline 6MWD m & $301(197-470)$ & $435(325-484)$ & 0.055 & $210(150-264)$ & $235(162-358)$ & 0.117 \\
\hline SBP $\mathrm{mmHg}$ & 123 (109-138) & $129(118-144)$ & 0.137 & 135 (119-155) & $134(123-153)$ & 0.977 \\
\hline$D_{\text {Lco }} \%$ predicted & $58(42-71)$ & $61(43-79)$ & 0.400 & $43(28-50)$ & $39(29-52)$ & 0.850 \\
\hline eGFR $\mathrm{mL} \cdot \mathrm{min}^{-1}$ per $1.73 \mathrm{~m}^{2}$ & 78 (60-98) & $81(72-112)$ & 0.539 & $44(33-57)$ & $50(39-66)$ & 0.011 \\
\hline NT-proBNP $n g \cdot L^{-1}$ & $1266(390-2470)$ & $1440(545-2489)$ & 0.771 & $2178(932-5070)$ & $1761(814-5353)$ & 0.520 \\
\hline \multicolumn{7}{|l|}{ Comorbidities } \\
\hline Hypertension & $16(25 \%)$ & $15(45 \%)$ & 0.097 & $43(59 \%)$ & $45(62 \%)$ & 0.762 \\
\hline Diabetes mellitus & $8(13 \%)$ & $8(24 \%)$ & 0.140 & $24(33 \%)$ & $29(40 \%)$ & 0.394 \\
\hline Atrial fibrillation & $3(5 \%)$ & $3(9 \%)$ & 0.394 & $13(19 \%)$ & $22(30 \%)$ & 0.121 \\
\hline Ischaemic stroke & $1(1.5 \%)$ & $1(3 \%)$ & 0.630 & $5(7 \%)$ & $9(12 \%)$ & 0.434 \\
\hline Ischaemic heart disease & $4(6 \%)$ & $4(12 \%)$ & 0.375 & $9(12 \%)$ & $25(34 \%)$ & 0.002 \\
\hline \multicolumn{7}{|l|}{ Number of comorbidities } \\
\hline 0 comorbidities & $42(66 \%)$ & $14(43 \%)$ & & $18(25 \%)$ & $10(14 \%)$ & \\
\hline 1 comorbidity & $14(22 \%)$ & $9(27 \%)$ & 0.050 & $28(38 \%)$ & $18(25 \%)$ & 0.011 \\
\hline$\geqslant 2$ comorbidities & $8(12 \%)$ & $10(30 \%)$ & & 27 (37\%) & $45(66 \%)$ & \\
\hline \multicolumn{7}{|l|}{ Haemodynamic values } \\
\hline $\mathrm{mRAP} \mathrm{mmHg}$ & $8(4-11)$ & $7(5-15)$ & 0.694 & $8(4-12)$ & $7(5-10)$ & 0.683 \\
\hline $\mathrm{mPAP} \mathrm{mmHg}$ & $49(44-59)$ & $52(44-60)$ & 0.600 & $47(41-54)$ & $45(40-51)$ & 0.143 \\
\hline PAWP $\mathrm{mmHg}$ & $8(6-11)$ & $9(7-11)$ & 0.562 & $9(6-12)$ & $9(6-12)$ & 0.727 \\
\hline Cardiac index L. $\min ^{-1} \cdot \mathrm{m}^{-2}$ & $2.3(1.9-2.8)$ & $2.3(1.9-2.7)$ & 0.631 & $2.1(1.8-2.5)$ & $2.2(1.8-2.6)$ & 0.497 \\
\hline PVR Wood units & $10(8-13)$ & $10(6-14)$ & 0.484 & $10(8-13)$ & $8(6-10)$ & 0.005 \\
\hline \multicolumn{7}{|l|}{ PAH-targeted therapy } \\
\hline Single & $46(64 \%)$ & $26(72 \%)$ & & $59(75 \%)$ & 72 (86\%) & \\
\hline Dual & $18(25 \%)$ & $7(19 \%)$ & 0.545 & $14(18 \%)$ & $6(7 \%)$ & 0.114 \\
\hline Triple & $3(4 \%)$ & 0 & & 0 & 0 & \\
\hline No treatment & $5(7 \%)$ & $3(8 \%)$ & & $6(8 \%)$ & $6(7 \%)$ & \\
\hline \multicolumn{7}{|l|}{ Supportive therapy } \\
\hline Anticoagulants & $47(65 \%)$ & 18 (50\%) & 0.199 & 45 (57\%) & $57(68 \%)$ & 0.151 \\
\hline Diuretics & $43(60 \%)$ & $17(47 \%)$ & 0.327 & $60(76 \%)$ & $65(77 \%)$ & 0.829 \\
\hline Supplemental oxygen & $10(14 \%)$ & $5(14 \%)$ & 0.600 & $37(47 \%)$ & $36(43 \%)$ & 0.610 \\
\hline
\end{tabular}

Data are presented as median (interquartile range) or $\mathrm{n}(\%)$ unless otherwise stated. WHO-FC: World Health Organization functional class; BMI: body mass index; 6MWD: 6-min walking distance; SBP: systolic blood pressure; $D_{1}$ : diffusing capacity of the lung for carbon monoxide; eGFR: estimated glomerular filtration rate; NT-proBNP. N-terminal pro-brain natriuretic peptide; mRAP: mean right atrial pressure; MPAP: mean pulmonary arterial pressure; PAWP: pulmonary arterial wedge pressure; PAH: pulmonary arterial hypertension. 

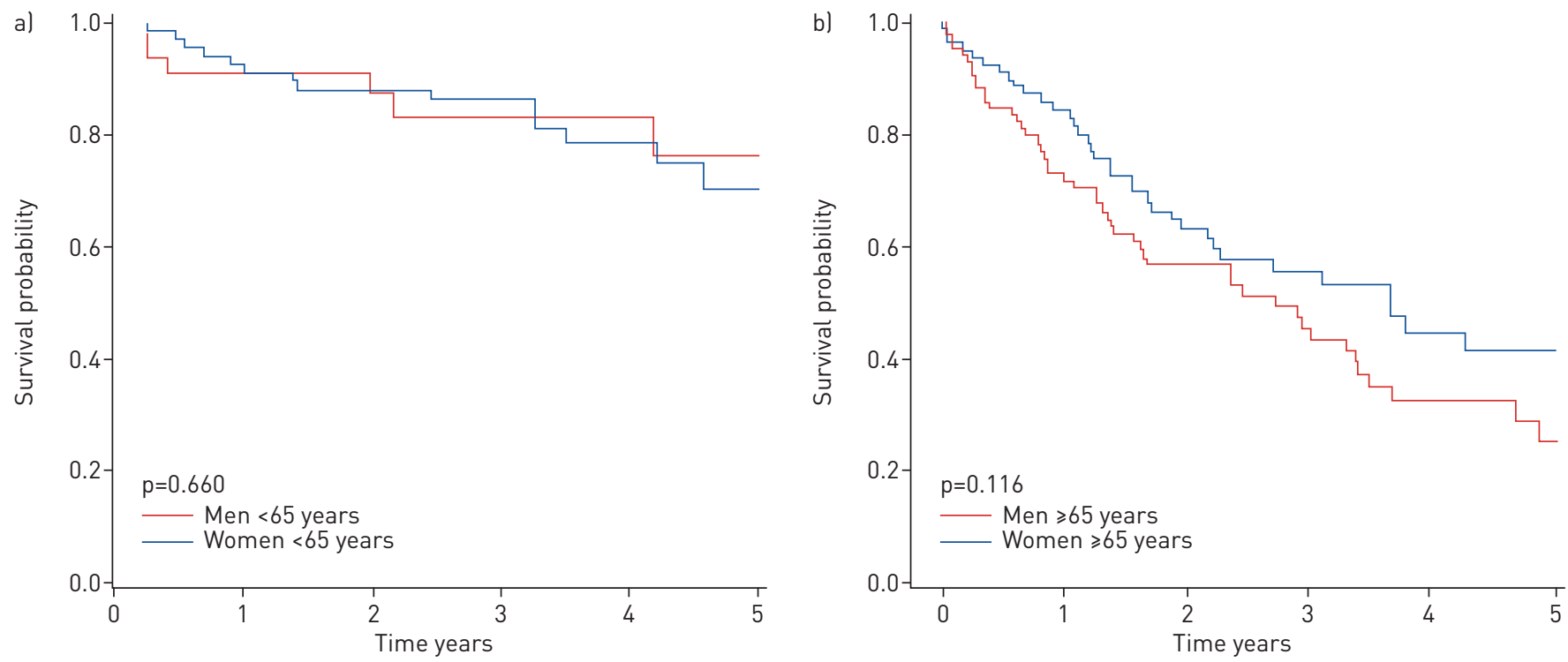

FIGURE 2 Survival of patients stratified by sex. a) Patients aged $<65$ years $(n=108)$; b) patients aged $\geqslant 65$ years $(n=163)$.

have added to the chance of receiving the right therapy from the start. To better understand this, further studies are needed to explore the sex differences in clinical response to PAH-targeted drugs.

Compared with previous studies, the patient population was older and the proportion of men was higher in the present study $[11-15,19]$. A contributing factor might be that the present study population was diagnosed between 2008 and 2016, a period with modern treatment available to all included patients. The increased awareness and the developing diagnostic and treatment options of PAH during this time period, combined with easier access to investigations such as ECGs in primary care, might have led to more systematic diagnostic routines and earlier referral for both women and men and at a higher age. Of course, other, unknown factors could also contribute to more equal baseline characteristics and survival among sexes.

SPAHR reflects not only an incident IPAH population, but also a real-life population that includes more than $90 \%$ of all patients with IPAH diagnosed in Sweden since $2008[3,6,16]$. This might be a putative explanation for the older population and difference in the proportion of women and men compared with earlier studies. The comorbidity burden likely reflects the older age, where a third of men aged 65 years or older have a history of ischaemic cardiovascular disease. This did not affect survival in an independent matter, despite a trend in the survival curves, and one might speculate that IPAH, a disease with a deleterious prognosis, shadows the effect of other comorbidities in this older age group. The IPAH diagnosis was made according to the ESC/ERS guidelines $[1,17]$ and thus, pulmonary hypertension due to left heart disease has been excluded.

The findings in the present study add to the knowledge that should be considered when evaluating and improving the growing number of instruments for risk assessment among patients with $\mathrm{PAH}$; the question of whether nonmodifiable factors should be included in the risk assessment algorithm or not is highly interesting. In the REVEAL (Registry to Evaluate Early And Long-Term Pulmonary Arterial Hypertension Disease Management) risk score, both male sex and age $\geqslant 60$ years are included as risk factors for worse survival $[12,29,30]$. While the present study supports age as a natural risk factor, male sex does not seem to affect survival by itself. The analysis behind the REVEAL risk score was indeed systematic and thorough, but it included only a total of $21 \%$ men, of which less than a third were older than 60 years [12, 30]. In the present study the proportion of men was twice as high (44\%) and even higher among patients in the older group ( $\geqslant 65$ years) that included $52 \%$ men. This higher proportion of men in the older age group might partly explain why survival, after adjusting for age, was similar between sexes in the present study. However, further and multinational studies are needed to confirm these findings and before adding or changing variables in existing risk score strategies.

\section{Conclusion}

Women were younger and had less comorbidities than men at the time of diagnosis, whereas the worse survival rate for men were age dependent. Thus, in patients diagnosed with IPAH between 2008 and 2016 , 
the survival rates for men and women were similar when considering natural confounders such as age and comorbidity.

\section{Strengths and limitations}

A major strength of the present study was that the analyses included only incident patients diagnosed with IPAH after 2008, providing a homogenous study group with respect to treatment strategies. Also, all PAH centres in Sweden participated in SPAHR $[6,16]$ and thus, more than $90 \%$ of all patients diagnosed with IPAH in Sweden since 2008 were included. Thus, data from this national register reflect a real-life patient population, as seen in clinical practice, compared with data collected in clinical trials. This is reflected in the high number of comorbidities reported in the group aged $\geqslant 65$ years. Though all patients met the diagnostic criteria for PAH according to the ESC/ERS guidelines [1, 17], the combination of hypertension, diabetes mellitus and atrial fibrillation might indicate that some patients had a diastolic dysfunction. This might also have affected the sex difference in upfront combination treatment. Limitations typically associated with observational registry studies, such as a lack of standardisation of registered variables and missing data exist in the presented study. The relatively small number of patients may have affected the power of the analysis; however, in light of IPAH being an unusual disease, it is difficult to achieve large national study groups.

Acknowledgements: We acknowledge the work of the SPAHR registrars at the seven PAH centres, Uppsala Clinical Research Centre and members of the SPAHR steering committee; Roger Hesselstrand, Kjell Jansson, Björn Kornhall, Henrik Ryftenius, Maria Selin, Stefan Söderberg and Maria Willehadson.

Conflict of interest: None declared.

Support statement: During the initiation of SPAHR, Actelion Pharmaceuticals Sweden AB, Bayer Health Care, Eli Lilly Sweden, Glaxo-SmithKline, NordicInfu Care and Pfizer gave financial support. Since 2011, SPAHR has qualified as a national quality register and the Swedish Association of Local Authorities and Regions give financial support. The financial supporters had no role in the data collection, analysis or interpretation and had no right in disapproving the manuscript.

\section{References}

1 Galiè N, Humbert M, Vachiery JL, et al. 2015 ESC/ERS Guidelines for the diagnosis and treatment of pulmonary hypertension: The Joint Task Force for the Diagnosis and Treatment of Pulmonary Hypertension of the European Society of Cardiology (ESC) and the European Respiratory Society (ERS): Endorsed by: Association for European Paediatric and Congenital Cardiology (AEPC), International Society for Heart and Lung Transplantation (ISHLT). Eur Heart J 2016; 37: 67-119.

2 Kylhammar D, Kjellström B, Hjalmarsson C, et al. A comprehensive risk stratification at early follow-up determines prognosis in pulmonary arterial hypertension. Eur Heart J 2017; 39: 4175-4181.

3 Hjalmarsson C, Rådegran G, Kylhammar D, et al. Impact of age and comorbidity on outcome in idiopathic pulmonary arterial hypertension. Eur Respir J 2018; 51: 1702310.

4 Badesch DB, Raskob GE, Elliott CG, et al. Pulmonary arterial hypertension: baseline characteristics from the REVEAL Registry. Chest 2010; 137: 376-387.

5 Humbert M, Sitbon O, Chaouat A, et al. Pulmonary arterial hypertension in France: results from a national registry. Am J Respir Crit Care Med 2006; 173: 1023-1030.

6 Rådegran G, Kjellström B, Ekmehag B, et al. Characteristics and survival of adult Swedish PAH and CTEPH patients 2000-2014. Scand Cardiovasc J 2016; 50: 243-250.

7 Hoeper MM, Huscher D, Ghofrani HA, et al. Elderly patients diagnosed with idiopathic pulmonary arterial hypertension: results from the COMPERA registry. Int J Cardiol 2013; 168: 871-880.

8 Ling Y, Johnson MK, Kiely DG, et al. Changing demographics, epidemiology and survival of incident pulmonary arterial hypertension: results from the pulmonary hypertension registry of the United Kingdom and Ireland. Am J Respir Crit Care Med 2012; 186: 790-796.

9 Smith AM, Jones RD, Channer KS. The influence of sex hormones on pulmonary vascular reactivity: possible vasodilator therapies for the treatment of pulmonary hypertension. Curr Vasc Pharmacol 2006; 4: 9-15.

10 Loyd JE, Primm RK, Newman JH. Familial primary pulmonary hypertension: clinical patterns. Am Rev Respir Dis 1984; 129: 194-197.

11 Jacobs W, van de Veerdonk MC, Trip P, et al. The right ventricle explains sex differences in survival in idiopathic pulmonary arterial hypertension. Chest 2014; 145: 1230-1236.

12 Shapiro S, Traiger GL, Turner M, et al. Sex differences in the diagnosis, treatment, and outcome of patients with pulmonary arterial hypertension enrolled in the registry to evaluate early and long-term pulmonary arterial hypertension disease management. Chest 2012; 141: 363-373.

13 Humbert M, Sitbon $\mathrm{O}$, Chaouat A, et al. Survival in patients with idiopathic, familial, and anorexigen-associated pulmonary arterial hypertension in the modern management era. Circulation 2010; 122: 156-163.

14 Weatherald J, Boucly A, Chemla D, et al. Prognostic value of follow-up hemodynamic variables after initial management in pulmonary arterial hypertension. Circulation 2018; 137: 693-704.

15 Ventetuolo CE, Praestgaard A, Palevsky HI, et al. Sex and haemodynamics in pulmonary arterial hypertension. Eur Respir J 2014; 43: 523-530.

16 SPAHR. Årsrapport [Annual report]. www.ucr.uu.se/spahr/arsrapporter. Date last accessed: 15 May 2019. Date last updated: 14 March 2019.

17 Galiè N, Hoeper MM, Humbert M, et al. Guidelines for the diagnosis and treatment of pulmonary hypertension. Eur Heart J 2009; 30: 2493-2537. 
18 Cockcroft DW, Gault MH. Prediction of creatinine clearance from serum creatinine. Nephron 1976; 16: 31-41.

19 Kawut SM, Al-Naamani N, Agerstrand C, et al. Determinants of right ventricular ejection fraction in pulmonary arterial hypertension. Chest 2009; 135: 752-759.

20 Nickel N, Golpon H, Greer M, et al. The prognostic impact of follow-up assessments in patients with idiopathic pulmonary arterial hypertension. Eur Respir J 2012; 39: 589-596.

21 Hoeper MM, Kramer T, Pan Z, et al. Mortality in pulmonary arterial hypertension: prediction by the 2015 European pulmonary hypertension guidelines risk stratification model. Eur Respir J 2017; 50: 1700740.

22 Boucly A, Weatherald J, Savale L, et al. Risk assessment, prognosis and guideline implementation in pulmonary arterial hypertension. Eur Respir J 2017; 50: 1700889.

23 Sitbon O, Gaine S. Beyond a single pathway: combination therapy in pulmonary arterial hypertension. Eur Respir Rev 2016; 25: 408-417.

24 Burks M, Stickel S, Galiè N. Pulmonary arterial hypertension: combination therapy in practice. Am J Cardiovasc Drugs 2018; 18: 249-257.

25 Mathai SC, Hassoun PM, Puhan MA, et al. Sex differences in response to tadalafil in pulmonary arterial hypertension. Chest 2015; 147: 188-197.

26 Gabler NB, French B, Strom BL, et al. Race and sex differences in response to endothelin receptor antagonists for pulmonary arterial hypertension. Chest 2012; 141: 20-26.

27 Galiè N, Barberà JA, Frost AE, et al. Initial use of Ambrisentan plus tadalafil in pulmonary arterial hypertension. N Engl J Med 2015; 373: 834-844.

28 Wilkins MR, Paul GA, Strange JW, et al. Sildenafil versus Endothelin Receptor Antagonist for Pulmonary Hypertension (SERAPH) study. Am J Respir Crit Care Med 2005; 171: 1292-1297.

29 Benza RL, Miller DP, Gomberg-Maitland M, et al. Predicting survival in pulmonary arterial hypertension: insights from the Registry to Evaluate Early And Long-Term Pulmonary Arterial Hypertension Disease Management (REVEAL). Circulation 2010; 122: 164-172.

30 Benza RL, Farber HW, Frost A, et al. REVEAL risk scores applied to riociguat-treated patients in PATENT-2: impact of changes in risk score on survival. J Heart Lung Transplant 2018; 37: 513-519. 